\title{
Analysis on the Development Trend of Star-rated Hotels Based on the Concept of Big Data Construction in Smart Cities
}

\author{
Yuanchun Huang ${ }^{1}$ and Bingjie $\mathrm{Xu}^{2}$ \\ ${ }^{1}$ Bohai University College of Management \\ ${ }^{2}$ Shenyang Agricultural University College of Economic and Management
}

Keywords: Star-rated hotels; Big data; Smart city; Development trends

\begin{abstract}
Since the 21st century, with the development of Internet, cloud computing, big data and mobile networks, Smart city has become the new model for the development of cities. The research on smart city s also flourishes. There are more than 400 cities in China which have started to construct smart city recently. Smart city construction has blossomed in China. The components of a smart city are divided into five aspects: smart industy, smart management, smart management, smart life and smart technology infrastructure. On the basis of the idea of building a smart city, use big data to analyzed the current situation and future development trend of star-rated hotels in China.
\end{abstract}

\section{Development status of Star-rated Hotels in China}

The data of this report are derived from the statistical bulletin issued by China National Tourism Administration. It shows that by of the end of 2016,there were 9,864 star-rated hotels in China, which consisted of 71 one-star hotels, 1,771 two-star hotels, 4,856 three-star hotels and 2,363 four-star hotels and 800 five-star hotels. According to the statistics, the following characteristics are shown in the China's star-rated hotels.

\section{Industry Scale}

1.1The Quantity of Star-rated Hotels

Influenced by policies and marked psychology, the number of star-rated hotels presented a trend of increasing first and decreasing over the recent 10 years. The total number reached the peak in 2009, then decreased from 2010 to 2016.

1.2Quantity of Rooms

By the end of 2016, the quantity of China's star-rated hotel rooms was $1,420,500$. In the past ten years, the number of rooms and the number of star-rated hotels shared the similar curve. In 2009, the total number of star-rated hotels reached the maximum. Which the number of hotel rooms continued to decrease from 2010 to 2016.

1.3Quantity of Beds

By the end of 2016, the total number for the beds in star-rated hotel rooms was $2,482,800$. In the past ten years, the number of beds showed a relatively large fluctuation, jumping to a peak was $3,064,700$ in 2009 and crashing to a low was 2,566,400 in 2010. Overall, the number of beds in nationwide star-rated hotels remained at an average about 2,560,000 beds each year. The Graph shows a negative growth, but the reduction is limited.

1.4Fixed Assets Scate

By the end of 2016, the total fixed assets of nationwide star-rated hotels totaled 517,454 bn yuan, down by $5.25 \%$ than the previous year. In recent years, the scale of fixed assets has been on the rise, climbing up to the peak in 2015 but declining in 2014 and 2016, showing the characteristics to adjust the huge volatility.

\section{Regional Distribution}

2.1Quantity Distribution

According to the distribution of the quantity, there was no huge volatility for the distribution of nationwide star-rated hotels. In particular, East China had the largest number of star-rated hotels, with the total number of 2707, accounting for 27.45\%; North China had 1219 star-rated hotels, accounting for $12.36 \%$ of the total; Central China had 1484 star-rated hotels, accounting for $15.05 \%$ 
of the total; Northwest China had 1090 star-rated hotels, accounting for $11.05 \%$ of the number of the total; Northeast China had 716 star-rated hotels, accounting for $7.26 \%$ of the total.

Among the regions mentioned above, only Central China had a modest increase in quantity, while the rest regions had fewer and fewer star-rated hotels instead in different degrees. The quantity for Northwest China dropped by $13.97 \%$ year on year, the quantity for North China fell by $13.2 \%$, the quantity for Southwest China fell by $11.71 \%$, the quantity for East China fell by $7.26 \%$, the quantity for Northeast China fell by $7.13 \%$ and the quantity for South China fell by $6.26 \%$.

2.2Fixed Assets Distribution

From the distribution of fixed assets by regions, the scale of fixed assets of star-rated hotels in China has presented different changing characteristics. In 2016, the fixed assets of star-rated hotels in East China had the biggest amount of $169.303 \mathrm{bn}$ yuan, representing $32.72 \%$ of the total number. Central China had the fixed assets of 49.597 bn yuan, representing $9.6 \%$ of the total and South China had the fixed assets of 77.632 bn yuan, $15 \%$ of the total. Among the above regions, only the fixed assets for central China rose by $12.25 \%$, while other regions declined in different degrees. South China dropped by $18.6 \%$ year on year. East China dropped by $15.83 \%$, Northeast China dropped by $12.7 \%$, Southwest China dropped by $10.1 \%$, North China dropped by $6.58 \%$, and Northwest China dropped by $0.5 \%$.

\section{Human Resource}

\subsection{Hotel Employees}

By the end of 2016, there were $1.1966 \mathrm{~m}$ employees working in nationwide star-rated hotels. From the year 2009, the total number of star-rated hotels staff, except 2012, has shown a declining trend. The number of hotel staff in 2016 dropped by 11\%, the largest decline over the previous years. According to the analysis of statistics, per capita fixed asset value was 432,500yuan, per capita operational revenue was 169,400yuan, per capita revenue profit was 393.62yuan. Overall, the labor productivity of star-rated hotels was at a lower level.

\subsection{Employees of Hotels with Different Star Grade}

As for hotels with different star grade, the quantity of hotel staff has been decreasing. Four-star hotels had the number of 432,000, which was the largest among different star grade, down by $6.49 \%$; the number of staff for three-star hotels totaled 396,800 , down by $17.44 \%$; the number of staff for two-star hotels totaled 64,100, down by $30.77 \%$; the number of staff for one-star hotels totaled 1,100 , down by $39.79 \%$. Compared with other star-rated hotels, the total number of staff in five-star hotels was stable, without noticeable change.

\subsection{Staff to Room Ratio}

Regarding the operational efficiency index made by staff to room ratio, the ratio for nationwide star-rated hotels in 2016 was 0.84 , down by 0.08 year on year, decreasing by $8.70 \%$, Each hotel employee managed 1.19 rooms on average, .01 room increased than that of 2015 . The staff to room ratio of five-star hotels was 1.10 , decreased by 0.04 year on year, down by $3.51 \%$, with each hotel employee managing 0.91 room, 0.03 room more than in 2015; the ratio of four-star hotels was 0.92 , 0.06 room reduced year on year, down by $6.12 \%$, with each hotel employee managing 1.09 rooms, 0.07 rooms more than 2015 .

\section{Analysis on the Development Trend of Star-rated Hotels Under Big Data}

\section{Nationwide Star-rated Hotels Turn from Deficits to Profits, with Main Business Indicators Improved}

In 2016, the main business indicators of star-rated hotels started to pick up. The average room occupancy rate was $54.73 \%, 0.54$ percentage points improved from the previous year. RevPAR was 183.10 yuan per room/night, up by $0.4 \%$ over the previous year. OLP was 169,400 yuan, up by $8.1 \%$. Operational revenues of each hundred-yuan fixed assets was 39.18 yuan, with an increase of 0.6 yuan.

The downturn starting from 2013 almost is essentially over. After achieving a profit of 5.046 bn yuan in 2012, the star-rated hotel industry suffered a loss of over 2 bn yuan in 2013, 2014 was at the bottom of the downward cycle, with the loss enlarged to 5.9 bn yuan. Though the profitability of 
star-rated hotel industry recovered in 2015, it still lost 1.4 bn yuan. In 2016 the profits of star-rated hotel industry turned from deficits to porfits by achieving $471 \mathrm{~m}$ yuan. The profitability of star-rated hotels has been growing up from its lowest point in 2014, showing signs of mild recovery. However, because the profits for 2016 was obtained in the context of the transition from business tax to value-added tax, the stabilization and recovery of the star-rated hotel industry still requires continuous structural adjustment, innovation and development, and improvement of quality and efficiency.

\section{Hotels with Different Star Grade Show Different Operational Performance, Five-star Hotels Industry Enjoys Solid Position}

The profitability of different star-rated hotels presented different characteristics and trends. From 2012 to 2016, the profits made by five-star hotels were 5.478 bn yuan, 2.996 bn yuan, $568 \mathrm{~m}$ yuan, 1.902 bn yuan and 4.535 bn yuan respectively. The star-rated hotels still maintained a positive profit over these years, though suffering an earning downturn in 2014. In 2016, the profit of five-star hotels increased significantly by $138 \%$ over the previous year, with a net increase of $634 \mathrm{~m}$ yuan, or $33 \%$, in spite of the deduction of 1.999 bn yuan from the transition from business tax to VAT. On the contrary, the three and four-star hotels showed obvious downturn. From 2012 to 2016, the total annual profits of the three-star and four-star hotels showed the loss of 4.79 bn yuan, 5.404 bn yuan, 6.719 bn yuan, 3.729 bn yuan and 4.241 bn yuan respectively, with a total loss of 20.572 bn in five years. In 2016, in particular, the lossed of three or four-star hotels still expanded compared with that of the previous year, and the operational conditions were not optimistic despite the tax deduction of 4.755 bn yuan due to the transition from business tax to VAT. The current round of operation for star-rated hotel industry had no obvious impact on one or two-star hotels. By the end of 2016 one and two-star hotels have been kept making porfits.However, they only made a 5 years' profits of 1.176 bn yuan due to their small size.

\section{Star-hotel Industry Seeking Porgress While working to keep Operation Stable, Supply-side Strucutural Reform Being Under Way}

Since 2014, the number of star-rated hotels has been shrinking year by year. In 2016, the number of star-rated hotels in the statistical communique total 9861 . The reduction of the total number of star-rated hotels indicated the profound changes from the continous adjustment of industry structure on the one hand, and also reflected the psychological impact brought by market development and policy factors on the other hand. From 2013 to 2016, though the total number of star hotels decreased, the number of five-star hotels got improved year by year, with a cumulative increase of 61 , an increase of $8.3 \%$ from 2013 . The number of four-star hotels has been ups and downs with the total number equal to that of 2013, a total increase of two four-star hotels. However, the hotels from one to three-star, by contrast, were dramatically reduced, decreased by 1889 within four years, down by $20 \%$. The number of the two-star hotels decreased by the maximum of 1060 and the number f one-star hotels were reduced by the sharpest margin, down by $43.2 \%$ over the past four years.

Consistent with the reduction in the number of star-rated hotels, the total operational revenue also dropped accordingly. From 2013 to 2016, the operational revenue of star-rated hotels has decreased by $16.6 \%$ in total, among which the operational revenue of five-star hotels increased slightly by $0.3 \%$, the other star-rated hotels, from one-star to four-star, showed the situation that the lower the stars, the lower the operational revenues. The operational revenues for hotels from one to four star were decreased by $61.8 \%, 37.7 \%, 23.4 \%$ and $9.4 \%$ respectively. Structural adjustment was also reflected in the employees. The number of the employees in star-rated hotels in 2016 was $1,196,600$, a decrease of $11 \%$ over the previous year. The number of employees in each star-rated hotels industry dropped since the previous year. The higher the star grade, the less the decline rate. The decline of employees working in one to five star-rated hotels were $39.79 \%, 30.77 \%, 17.44 \%, 6.49 \%$ and $1.59 \%$ respectively. Decline in the number of star-rated hotels was the result of a combined effect of the reduced hotels size and human resource efficiency brought by the use of new technologies. Scale reduction was the dominant factor for low star-rated hotels while human resource efficiency was the dominant factor for high-star hotels. Though the 
number of employees was reduced, more and more employees with college degree ro above was hired in star-rated hotels. In 2016, the number of employees with college degrees or above was 259,000 , up $1.01 \%$ over the previous year and accounting for $21.64 \%$ of the total number of the employees in star-rated hotels, an increase of 2.57 percentage points over the previous year. The quality of employees has been improved to a certain extent.

4. The Total Amount of Fixed Assets Is Relatively High, while the Growth Rate Slows Down

In 2016, the fixed assets of nationwide star-rated hotels reached 517.454 bn yuan. The fixed assets of nationwide star-rated hotels industry exceeded 500 bn yuan for four consecutive years, and the total amount of statistics dropped slightly compared with the same period last year. From 2006 to 2016, the total fixed assets of star-rated hotels in China increased by 121.709 bn yuan, an increase of $30.75 \%$. Overall, the growth trend was maintained with show growth rate, and the industry entered the structural adjustment period from a rapid expansion period, as was shown by the characteristics of oscillation adjustment. From the perspective of the distribution of fixed assets, the proportion of state-owned capital was modestly higher than that of private capital, followed by other forms. However, the difference among all the proportions was not noticeable. From the changing trend, the state-owned capital has been gradually withdrawing, the total amount is showing a downward trend.

\section{Acknowledgement}

This paper serves as one of research results for "2015 Liaoning Provincial Fund Project for Social Science" (Registration No.: L15BJY010) and"2016 Education department of Liaoning Province" (Registration No:WY2016002)

\section{Reference}

[1] Huang Zhenfang, The Spatial Analysis of Relative Efficiency Agglomeration about Chinese Star-rated Hotels and Promotion Strategies, Human Geography, 2013.01

[2] Yang Yong, Seasonality about Star Hotel Room Occupancy Rate in Shanghai, Economic Geography, 2015.04

[3] Bao Fuhua, Study on Rank Size Dispartiy of Four Star Hotels in China Section of the Belt and Road, Resource Development\&Market,2017.10

[4] Yao Yanbo,Hou Pingping,Liu Yixue, Research on the High-star Hotel Attributes based on IPA Analysis, Commercial Research,2018.03

[5] Zhang Hong, Cheng Zhengdong, Evaluation and Analysis of Chinese Star-rated Hotels'Efficiency in Different Regions Based on Method of DEA, Resource Development\&Market, 2014.10 